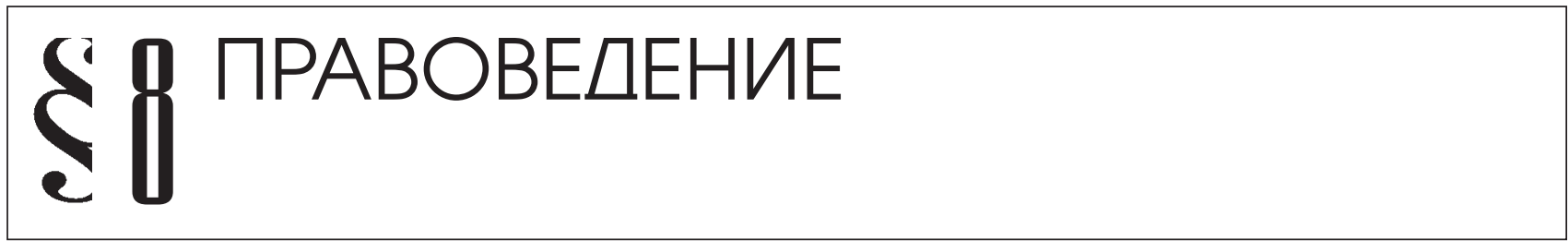

\title{
К ВОПРОСУ О НЕКОТОРЫХ АКТУАЛЬНЫХ ПРОБЛЕМАХ АДМИНИСТРАТИВНОГО ПРАВА ${ }^{1}$
}

\begin{abstract}
Аннотация: В статье рассматриваются ряд наиболее актуальных проблем науки административного права, а также правоприменительной практике в сфере государственного управления, экономики, финансов, в статье кратко описывается проблема, которая имеет место в той или иной сфере административно-правовой действительности, на основании чего делаются ряд выводов, приводятся наиболее авторитетнье точки зрения на проблему, которая является предметом рассмотрения в настоящей статье, а также точка зрения автора
\end{abstract}

Ключевые слова: Юриспруденция, проблема, право, регулирование, процесс, юрисдикция, актуальность, государство, аппарат, норма

B современный период развития нашего общества, реализация норм административного права является одной из самых актуальных задач государственно-правовой деятельности. Административноправовые нормы имеют огромное значение для всего общества в целом и для каждого человека в отдельности, поскольку в них представлена воля государства, выраженная через нормативные правовые акты его органов, касающиеся обеспечения прав и законных интересов граждан и хозяйствующих субъектов в сфере публичного управления. Нормы административного права выполняют огромную роль в регулировании, организации и функционировании государственного аппарата, обеспечивая посредством административных процедур и регламентов должное и своевременное определение позитивных общественных отношений в сфере государственного управления.

На науку административного права существенное влияние оказывает совершенствование и изменение российского законодательства, проводимые в России социально-экономические и политические реформы, а также различного рода структурные преобразования аппарата управления. Кроме того, в настоящее время усложняется правоприменительная практика, размывается предмет и объект административно-правового регулирования. Сегодня практически невозможно найти сферу общественных отношений, которая бы не осталась

${ }^{1}$ Статья подготовлена при информационной поддержки компании «Консультант Плюс». без административно-правового воздействия. Нормы административного права наиболее гибко и дифференцированно воздействуют на общественные отношения, упорядочивая и охраняя их. В Как уже отмечалось, необходимо признать, что в современном обществе именно нормы административного права в наибольшей степени социально востребованы и необходимы² ${ }^{2}$

Значимость административного законодательства, а также в целом норм административного права ранее привлекало и привлекает существенное внимание ученых и специалистов практиков. Учитывая имеющуюся тенденцию развития юридической науки, можно с уверенностью утверждать, что наука административного права будет и в дальнейшем интенсивно и перспективно развиваться.

Необходимо отметить, что многие проблемы административно-правового регулирования уже были предметом научного исследования, но, тем не менее, утверждать, что в настоящее время решены все проблемы в рассматриваемой сфере, пока невозможно. В представленной статье обобщен обширный научный опыт автора, который на протяжении многих лет изучал реализацию норм административного права в различных сферах государственного управления ${ }^{3}$, а также высказывался по некоторым существенным проблемам науки административного права.

\footnotetext{
${ }^{2}$ См.: Костенников М.В., Куракин А.В. Актуальные проблемы науки административного права. - М., 2011. - С. 6.

${ }^{3}$ См.: Костенников М.В., Куракин А.В. Актуальные проблемы административно-правового регулирования. - М., 2010. - С. 5.
} 
1. Проблема. Правовое регулирование общественных отношений в сфере административно-правовой действительности осуществляется через систему правовых средств, которые между собой логически взаимосвязаны. От того насколько эффективны соответствующие средства, насколько правильно они определены, зависит качество правового воздействия на соответствующие общественные отношения. Совокупность правовых средств, с помощью которых происходит правовое воздействие, получило название «механизм правового регулирования».

Основоположником в исследовании вопросов действия механизма правового регулирования стал С.С. Алексеев. В своей работе «Механизм правового регулирования в социалистическом государстве» он дает следующее определение: «механизм правового регулирования - это взятая в единстве совокупность юридических средств, при помощи которых обеспечивается правовое воздействие на общественные отношения» ${ }^{4}$. С.С. Алексеев говорит о том, что рассматриваемая категория позволяет не только собрать вместе явления правовой действительности, связанные с решением жизненных ситуаций, и обрисовать их как целостность, но и представить их в работающем, системно воздействующем виде 5 .

Составляющими элементами механизма правового регулирования, по мнению С.С. Алексеева, являются: правовые нормы, правоотношения, акты применения норм права, правовая культура и правосознание. Он отмечает, что процесс правового регулирования включает в себя три основные стадии: регламентирование общественных отношений, действие юридических норм, реализацию субъективных юридических прав и обязанностей. Трем названным стадиям, по мнению С.С. Алексеева, соответствуют три основных элемента, или части механизма правового регулирования:

- юридические нормы;

- правоотношения;

- $\quad$ акты реализации субъективных юридических прав и обязанностей.

В качестве «не основных» элементов механизма правового регулирования С.С. Алексеев называет нормативные юридические акты, а также правосознание и правовую культуру ${ }^{6}$.

Однако, как отмечает А.П. Шергин, «...проблемы механизма административно-правового регулирования не получили достойного внимания в современной юридической литературе, особенно в административном праве,

\footnotetext{
${ }^{4}$ Алексеев С.С. Механизм правового регулирования в социалистическом государстве. - М., 1966. - С. 30.

${ }^{5}$ См.: Алексеев С.С. Право. Опыт комплексного исследования. - М., 1999. - С. 364 .

${ }^{6}$ См.: Там же. - C. 34.
}

так как усилия ученых-административистов были ориентированы на разработку преимущественно отдельных элементов рассматриваемого механизма (административно-правовых норм, административных правоотношений и др.). Механизм правового регулирования в соответствующей отрасли права подчиняется специфике предмета правового регулирования ${ }^{7}$.

Исходя из этого, можно сделать вывод, что в каждой отрасли права содержится свой правовой механизм, содержание которого обусловлено отраслевой спецификой. Проблема механизма правового регулирования в современный период разработана не столь обстоятельно, в этой связи в содержание соответствующего механизма включаются самые разнообразные правовые средства, которые играют в нем далеко не однозначную роль. На наш взгляд, в содержании правового механизма должны находиться лишь средства, которые самым непосредственным образом могут воздействовать на отношения, регулировать которые они призваны. Включение же каких-то «не обязательных средств» только размоет ядро механизма правового регулирования вообще и механизма административно-правового регулирования, в частности.

Таким образом, механизм административно-правового регулирования представляет собой совокупность правовых средств, которые самым непосредственным образом воздействуют на общественные отношения, складывающиеся в сфере административно-правовой действительности, упорядочивают их, а также делают легитимными. Для того, чтобы механизм административно-правового регулирования работал, в его содержании, прежде всего, должны быть нормы права, правоотношения, а также правоприменительные акты.

Нужно особо отметить, что нормы административного права занимают центральное место в механизме административно-правового регулирования, именно нормы права - тот сходный компонент, без которое невозможно представить механизм правового регулирования. Напомним, что норма административного права - это общегосударственное установление, которая призвано регламентировать самые разнообразные общественные отношения, складывающиеся в сфере административно-правовой действительности, а именно - отношения управленческого характера, полицейские отношения, административно-деликтные отношения и др., выполнение предписаний нормы административного права обеспечивается мерами государственного воздействия как принудительного, так и не принудительного характера. Следует отметить, что нормы административного права в современный период регламентируют не только

\footnotetext{
${ }^{7}$ См.: Шергин А.П. К концепции механизма административноправового регулирования // Административное и административно-процессуальное право. - М., 2004. - С. 102.
} 


\section{Право и политика 5 (161) 2013}

публичные, но и частные общественные отношения. В целях улучшения качества норм административного права в настоящее время необходима их системная кодификация. Кодификация норм административного права - это процесс систематизации соответствующих норм, которое производит государство. Кодификации нормативного материала - процесс объективно необходимый, поскольку рано или поздно нужно пересматривать нормативный материал, принимать документы более высокой юридической силы, а также уточнять нормативные формулировки. Следует отметить, что кодификация норм административного права осуществляется по отраслям и сферам правового регулирования, кодификация и кодекс категории хоть и близкие, но далеко не тождественные. Кодификация норм административного права осуществляется в различных формах - это принятие федерального закона, основ законодательства, кодексов и др. В современный период с учетом потребностей правоприменительной практики, необходимо принятие Административно-процессуального кодекса, а с учетом накопившегося законодательного и иного нормативного правового материала - Полицейского кодекса Российской Федерации.

Административные правоотношения также являются обязательным элементом механизма правового регулирования. Административные правоотношения всегда носят динамичный характер, одной из особенностей административных правоотношений является то, что в этих отношениях очень гибко переплетается материальная и процессуальная составляющие. В современный период границы административных правоотношений весьма существенно расширились. В силу объективных причин, а также специфики публичного управления в административные правоотношения органично вплелись и отношения частноправового характера, которые не могут быть реализованы без регулятивных свойств, как норм административного права, так и административных правоотношений.

Необходимо упомянуть об административных правоприменительных актах - это то, без чего механизм правового регулирования, нормы права и правоотношения так и останутся без движения. Административный правоприменительный акт задает вектор всему правоприменительному процессу. Эти акты также как и нормы и правоотношения весьма разнообразны, они могут носить как регулятивный (позитивный) характер, так и охранительный (принудительный) характер. Во всех случаях в административных правоприменительных актах заложена энергия государства, его власть - связано это с тем, что субъектом вынесения (принятия) соответствующих правоприменительных актов является должностное лицо органа власти или управления.

2. Проблема. Управленческие отношения занимают центральное место в предмете административно-правового регулирования. Несмотря на это, управленческие отношения являются предметом регулирования конституционного права, финансового права и др. Нормы административного права в механизме государственного управления определяют формы и методы управленческой работы, определяют статус субъектов управления. Однако, не взирая на то, что управленческие отношения занимают одно из главных мест в предмете административного права, все же эти отношения носят вторичный характер по отношению к полицейским отношениям. Традиционно считалось, что управленческие отношения это отношения исключительно власти - подчинения. Однако в современный период такой подход верен далеко не вполной мере. Развитие института государственных услуг, которые предоставляют в ходе своей исполнительно-распорядительной деятельности органы власти и управления, предполагает по большей своей части отношения горизонтального характера, где императивные методы воздействия уже не работают.

Вопросы государственного управления и административного права диалектически взаимосвязаны. В этой связи рассмотрим, что понимается под государственным управлением в теории. В настоящее время одной из проблем, с которой сталкивается правоприменительная практика, это отсутствие в законодательстве понятия «государственного управления», хотя в названиях различных документов эта категория начала встречаться достаточно часто. Многообразие понятия «управление» обусловлено множеством процессов и явлений, которые относятся к управлению. Следует отметить несмотря на то, что в юридической литературе понятию «государственное управление» посвящено большое количество работ, его единого определения и функций до сих пор выработано не было. Ю.М. Козлов пишет, что государственное управление по своему назначению представляет собой не что иное, как вид государственной деятельности, в рамках которой практически реализуется исполнительная власть ${ }^{8}$.

Г.В. Атаманчук указывает, что государственное управление есть организующее и регулирующее воздействие государства на общественную жизнедеятельность людей в целях ее упорядочивания, сохранения, или преобразования, опирающегося на его властную силу 9 .

Государственное управление - это то, без чего не может функционировать ни одно государство. Государственное управление является составной частью социального управления. Государственное управление осуществляется по широкому спектру проблем социальной действительности, в ходе его осуществления используются методы как прямого, так и косвенного воздействия. Для того, чтобы

\footnotetext{
${ }^{8}$ См.: Козлов Ю.М. Административное право. - М., 2002. - С. 20.

${ }^{9}$ См.: Атаманчук Г.В. Государственное управление (организационно-функциональные вопросы). - М., 2000. - С. 253.
} 
в современный период государственное управление было эффективно, необходимо совершенствовать формы и методы его реализации, а также укреплять режим законности и дисциплины во всех без исключения управленческих структурах. Следует подчеркнуть, что в научной литературе термин «государственное управление» пытались заменить на термин «публичное управление». Такую замену поддержать нельзя, поскольку это разные категории.

Одним из основных субъектов государственного управления являются органы исполнительной власти как федерального, так и регионального уровня, а также исполнительные органы местного самоуправления. Органы исполнительной власти имеют различную организационную форму, являются юридическими лицами административного права. От формы исполнительного органа государственной власти зависит его территориальная и предметная компетенция. Компетенция определяет предмет функционирования соответствующего органа исполнительной власти.

Формы реализации исполнительно-распорядительной деятельности реализуются через их нормативные правовые акты. Акты исполнительной власти - это продукт нормотворческой деятельности. Эти акты принимаются на основании и в исполнении федеральных законов, в них содержится механизм реализации положений законов, указов Президента России и др. Акты органа исполнительной власти принимаются соответствующим органом в пределах его компетенции и в установленной форме. Они также как и закон обязательны к исполнению всеми без исключения субъектами, к которым они адресованы. Обязательным требование, предъявляемое к этим актам это соответствие их закону или иному документу, который обладает большей юридической силой.

Говоря о проблеме государственной службы необходимо сказать, что это классический институт административного права, государственная служба является связующим звеном между государством и гражданином. Государственная служба имеет различные формы своего проявления это: военная служба, гражданская служба и правоохранительная служба. Все перечисленные виды государственной службы одинаково важны. Государственная служба олицетворяет собой государство, граждане формирует свое мнение о государстве через его служащих. В настоящее время государственная служба пребывает не в лучшем состоянии, высокий уровень коррупции, кадровая неразбериха сказываются на эффективности государственной службы различных видов ${ }^{10}$.

Одной из глобальных проблем современной российской государственности является проблема коррупции в органах власти и управления. Несмотря на развитие зако-

${ }^{10}$ См.: Куракин А.В. Административное право: проблемы теории и перспективы развития. - М., 2013. - С. 23. нодательства о противодействии коррупции ее уровень не снижается. Обусловлено это целым рядом причин как объективного, так и субъективного характера. Для снижения уровня коррупции необходимо устранить политическую целесообразность и конъюнктуру в антикоррупционной политике. Только при этом условии можно добиться позитивного результата ${ }^{11}$.

3. Проблема. Проблемы административного процесса начали привлекать внимание ученых сравнительно не так давно, хотя административно-процессуальные нормы объективно присутствовали в законодательстве всегда. Обусловлено это тем, что именно с помощью процессуальных норм осуществляется правоприменительный процесс. В науке административного права нет единого мнения относительно содержания административного процесса. Традиционно в содержании административного процесса включаются различные производства, которые систематизируются по различным критериям, в современный период в содержание административного процесса также включаются процедуры и регламенты. Возможно, после принятия Административно-процессуального кодекса проблема административного процесса получит свое разрешение.

В юридической науке в целом и науке административного права в частности, несмотря на предпринимаемые усилия, до настоящего времени не сформировано единое общепризнанное определение административного процесса. Это обстоятельство в значительной степени объясняется имеющимися среди исследователей разногласиями по вопросам о сущности, содержании и структуре административного процесса. Исследование проблем административного процесса в деятельности органов исполнительной власти показывает, что в настоящее время наблюдается такая ситуация, когда один и тот же термин несет разную смысловую нагрузку в зависимости от целого ряда факторов, контекста работы, особенностей авторского подхода к исследуемой проблеме и т.п.

Сегодня административный процесс в науке иногда отождествляют с управленческим процессом, административным судопроизводством, производством по делам об административных правонарушениях. Каждая из точек зрения весьма квалифицированна аргументирована. В действительности же, как представляется, административный процесс - это форма, в которую включаются различные виды управленческого процесса, позитивного административного процесса (административные процедуры и регламенты), административное судопроизводство, принудительный и охранительный административный процесс. Административная юрисдикиия - это часть ад-

\footnotetext{
${ }^{11}$ См.: Куракин А.В. Предмет административно-правового регулирования в механизме противодействия коррупции. - Домодедово, 2013. - C. 18.
} 


\section{Право и политика 5 (161) 2013}

министративного процесса, в ходе которого реализуются меры государственного воздействия, разрешаются различные управленческие конфликты и др. Административное производство - это главная составляющая административного процесса. Самым крупным административным производством является производство по делам об административных правонарушениях. Следует оговориться, что само производство, также состоит из определенного количества производств: административное расследование, производство по применению мер процессуального обеспечения и др.

Административные процедуры - это относительно новый элемент административного процесса, иными словами можно сказать, что это позитивная часть административного процесса, в ходе которого осуществляется предоставление государственных услуг, совершаются иные юридически значимые управленческие действия. Административный регламент - это процессуальный документ, который включает различные процедуры, регламент касается различных аспектов деятельности органа власти и управления, а также их должностных лиц. Административный регламент помогает минимизировать различные издержки при взаимодействии гражданина и должностного лица, в частности, при предоставлении гражданину какой-либо государственной услуги.

4. Проблема. Одной из актуальных проблем современного административного права, является проблема административной ответственности, как в материальном, так и в процессуальном аспекте. Значение института административной ответственности в механизме обеспечения правопорядка за последние годы резко возросло. Обусловлено это новыми административными наказаниями, которые, по сути, могут приостанавливать деятельность хозяйствующего субъекта, а также высокие суммы административных штрафов, которые применяются как к физическим, так и к юридическим лицам. Кроме того, одной из проблем административной ответственности является то, что это, по сути, единственный вид публично-правовой ответственности, находящейся в совместном ведении Российской Федерации и ее субъектов, что усиливает ее правоохранительный потенциал.

Делая вывод относительно актуальных проблем административной ответственности, представляется возможным сказать, что данный вид ответственности является одним из основных средств обеспечения правопорядка в сфере государственного управления. Однако на пути реализации мер административной ответственности имеется достаточно много правовых и организационных проблем. В действующем законодательстве об административных правонарушениях отсутствует определение административной ответственности, что нельзя признать позитивным. В научной литературе административная ответственность определяется как мера административного принуждения, применяемая как к физическим, так и к юридическим лицам. Меры административной ответственности - это административные наказания, состоящие как в имущественных, так и неимущественных правоограничениях, реализуемые в установленном процессуальном порядке. Принципы административной ответственности - это императивные законодательные предписания, на основании которых применяются установленные законом административные наказания.

Что касается оснований административной ответственности то ими являются административные правонарушения, которые обладают рядом признаков, позволяющих идентифицировать его из совокупности иных противоправных деяний совершаемых в административно-правовой сфере. Одним из содержательных признаков административного правонарушения должен являться признак общественной опасности. Добавление этого признака обусловлено тем, что деяния, за которое предусмотрено такое строгое административное наказание, просто не может не иметь признака общественной опасности.

В свою очередь состав административного правонарушения - это совокупность закрепленных в законе признаков, которые характеризуют противоправное деяние как правонарушение. Состав правонарушения включает объективные и субъективные признаки, которые в свою очередь включают обязательные и факультативные компоненты. Квалификация административных правонарушений - это правоприменительный процесс представляющий собой сопоставление как объективных, так и субъективных признаков состава административного правонарушения. Следует отметить, что в производстве по делам об административных правонарушениях принимают участие различные лица, у каждого из которых свой процессуальный статус, а также интерес в исходе дела.

5. Проблема. Современное административное право регламентируют самые разнообразные отношения в экономики, финансов, предпринимательстве, банковской деятельности. Без регулятивных и охранительных свойств норм административного права в названных сферах просто не обойтись. Насущная проблема сегодня сделать административно-правовое регулирование экономических и финансовых правоотношений наиболее оптимальным, снять необоснованные административные барьеры, запреты и ограничения, устранить необоснованное и чрезмерное государственное вмешательство в экономические отношения.

Так, в настоящее время предпринимательская деятельность осуществляется далеко не свободно, каждый субъект предпринимательства находится под действием различных правовых режимов. Основным правовым режимом, воздействующим на предпринимательскую деятельность, является именно административно-правовой 
режим. В этой связи представляется необходимым либерализовать некоторые административно-правовые средства воздействия в отношении хозяйствующих субъектов.

Если говорить об административно-правовом регулировании финансов, то следует отметить, что финансы - эта та сфера общественных отношений, которая в силу объективных причин просто не может быть вне административно-правового регулирования. Для осуществления соответствующего регулирования создаются различные федеральные органы исполнительной власти, создан институт административно-финансового контроля.

Следует также сказать, что и банки, как коммерческие структуры также являются субъектами административного права. Банки вступают в различные административные правоотношения с Центральным Банком, а также иными органами исполнительной власти.

6. Проблемы законности всегда находятся в центре внимания. Государственное управление, полицейская деятельность, защита прав граждан, просто немыслимы без должного режима законности и правопорядка. Законность обеспечивается различные правовыми и организационными средствами всеми без исключения органами государственной власти и управления. Без решения проблемы беззаконности просто невозможно проводить структурные преобразования, добиваться поставленных государственных целей. В этой связи проблема законности является сегодня одной из самых актуальных и востребованных. В современный период проблему укрепления законности нельзя рассматривать изолированно от проблем противодействия коррупции и укрепления дисциплины в органах власти и управления, а также проблемы построения правового государства. Правовое государство - это самая благоприятная среда для создания режима законности. Правовое государство в определенной степени - это своеобразная оболочка законности. Законность как явление общественной и государственной жизни возникала и развивалась постепенно, эволюционировала от простых форм к сложным формам и проявлениям. Интересно вспомнить, в этой связи, что В.М. Лесной верно замечал, что законность не существовала извечно. Впервые этот термин мы встречаем у идеологов правового государства Г. Гроция, Ш. Монтескье, Ж. Руссо, которые в своих трудах исследовали буржуазно-демократические принципы ${ }^{12}$.

Законность - это цель правового государства, его основополагающий результат. Именно к такому результату стремятся все государства и общества, однако в силу объективных причин для многих государств эта цель так

${ }^{12}$ См.: Лесной В.М. Советская социалистическая законность. M., 1959. - C. 10. и остается недостигаемой. Приходится констатировать, что большое количество законов, которые в настоящее время приняты как на федеральном, так и на региональном уровне, само по себе не формирует режим законности и дисциплины в органах власти и управления. Принятые законы, а также иные нормативные решения органов исполнительной власти, иногда создают неразбериху в правоприменительной практике, а также не способствуют укреплению режима законности, создавая в ряде случаев ситуацию для различного рода коррупционных правонарушений и иных должностных злоупотреблений. В настоящее время предстоит еще много сделать, что бы Закон начал эффективно работать и самым непосредственным образом помогал правоприменительным органам добиваться тех целей, а также решения тех задач, ради которых, собственно, и принимался соответствующий правовой акт. Законность в административном праве обеспечивается правовыми средствами данной отрасли права. Нормы административного права закрепляют такие средства как контроль, жалоба, ответственность и др.

Методы обеспечения законности в административном праве - это инструментарий, с помощью которого уполномоченные на то субъекты добиваются должного режима законности и правопорядка. Методы определяют качественную сторону процесса обеспечения законности во всех сферах административно-правовой действительности. Усмотрение в административном праве и проблемы законности между собой диалектически взаимосвязаны. В праве существуют различные виды усмотрения, которые имеют определенные особенности, обусловленные той сферой, в которой реализуется соответствующее право усмотрения. Административное усмотрение, в отличие от иных видов правового усмотрения охватывает обширный круг общественных отношений, складывающихся в сфере публичного управления. Носителями административного усмотрения является также достаточно широкий круг субъектов правоприменительной деятельности - от рядового служащего, чиновника, (сотрудника) до руководителя органа власти и управления. Занимаемая должность служащего или сотрудника органа власти или управления в одном случае может расширять границы административного усмотрения, в другом случае существенно его сужает. Иногда имеют место попытки подмены права административного усмотрения свободным усмотрением в разрешении того или иного вопроса. Интересно, что подобная практика существует в некоторых зарубежных государствах, и она достаточно успешно работает, если в обществе высок уровень правовой культуры и правосознания.

Право усмотрения дано правоприменителю для того, чтобы он действовал законно, оперативно, самостоятельно, а не для нарушения законности и произвола. 


\section{Право и политика 5 (161) 2013}

Правужалобы как средству обеспечения законности в административном праве принадлежит главенствующая роль в процессе обеспечения законности. В праве выделяются различные жалобы, каждая из которых по своему обеспечивает режим законности и правопорядка.

В целях совершенствования административноправового регулирования производства по жалобам граждан, а также хозяйствующих субъектов, назрела объективная необходимость принять Федеральный закон «О жалобах граждан и юридических лиц». В концептуальном плане, в Федеральном законе «О жалобах граждан и юридических лиц» необходимо определить специальные принципы производства по жалобам, сроки, а также порядок производства по жалобам. Принципиальным является положение о том, каким актом возбуждается производство по соответствующей жалобе, каким актом приостанавливается, а также то, каким актом оно прекращается.

В предлагаемом законе также целесообразно закрепить процессуальный механизм выявления, фиксации и закрепления доказательств, которые собраны в ходе производства по жалобе. Кроме того, в таком законе необходимо закрепить процессуальный статус участников производства по жалобам. В частности, следует определить права и обязанности должностного лица (служащего), действия (бездействие) или решение которого обжалуется, статус свидетелей. При этом необходимо обязательно указать на ответственность свидетеля за дачу заведомо ложных показаний в ходе производства по жалобе. За это может быть установлена как дисциплинарная, так и административная ответственность. Дисциплинарная ответственность должна касаться служащих, работников соответствующего органа, учреждения, которые выступают в качестве свидетелей в производстве по жалобе, а административная ответственность должна касаться граждан, которые участвуют в производстве по жалобам. В Федеральном законе «О жалобах граждан и юридических лиц», в отдельной статье должны быть закреплены меры пресечения, а также меры процессуального обеспечения производства по жалобам граждан и юридических лиц.

В предлагаемом законе «О жалобах граждан и юридических лиц» должно быть также определено, что служебная проверка проводится по решению руководителя органа власти и управления, в процессе которой следует объективно и всесторонне установить: факт обжалуемого деяния, время, место, обстоятельства его совершения, вину служащего, деяние или решение которого обжалуется, а также причинно-следственную связь между действиями (бездействием) служащего и наступившими последствиями. В приложении к предлагаемому закону необходимо поместить бланки процессуальных документов, которые составляются в ходе производства по жалобам.

Предлагаемый законодательный акт должен носить универсальный характер и, тем самым, исключить регламентацию принципиальных вопросов производства по жалобам граждан подзаконными нормативными правовыми актами федеральных органов исполнительной власти.

И, наконец, представляется уместным и своевременным отметь, что административные запреть как средство обеспечения законности в административном праве необходимы для сдерживания негативного поведения всех без исключения субъектов права. Запретов не должно быть много. Их должно быть ровно столько, сколько необходимо для обеспечения законности и правопорядка. Следует подчеркнуть, что административные запреты в системе государственной службы достаточно разнообразны. Перед каждой группой таких запретов стоят свои задачи, которые подчиняются общим задачам правового регулирования надлежащего служебного поведения, а также укреплению законности и правопорядка в системе государственной службы. Все многообразие запретов в системе государственной службы можно классифицировать по ряду критериев. В зависимости от сферы их реализации административные запреты дифференцируются на запреты, которые реализуются во внешней сфере деятельности служащего и запреты, которые реализуются внутри служебных отношений. Административные запреты могут быть дифференцированы также в зависимости от стадии реализации государственно-служебных отношений: запреты до начала осуществления государственной службы, в ходе осуществления государственной службы и после прекращения государственной службы. Административные запреты могут быть дифференцированы и в зависимости от вида государственной службы, а также статуса государственного служащего, они могут быть также классифицированы в зависимости от степени их общественной опасности и мер юридической ответственности, которые применяются за нарушение их предписаний.

Трудно переоценить значимость административного законодательства, именно его нормы в настоящее время в наибольшей степени социально востребованы. Сегодня «работу» норм административного права можно увидеть в деятельности органов государственной власти различного уровня, в сфере осуществления предпринимательской деятельности, сфере услуг, а также в деятельности самых различных структур, которые функционируют в рыночной экономике и свободном гражданском обществе. Решением представленных проблем, такую «работу» по-нашему мнению, можно существенно улучшить. 


\section{Библиография:}

1. Алексеев С.С. Механизм правового регулирования в социалистическом государстве. - М., 1966.

2. Алексеев С.С. Право. Опыт комплексного исследования. - М., 1999.

3. Атаманчук Г.В. Государственное управление (организационно-функциональные вопросы). - М., 2000.

4. Козлов Ю.М. Административное право. - М., 2002.

5. Костенников М.В., Куракин А.В. Актуальные проблемы административно-правового регулирования. - М., 2010.

6. Костенников М.В., Куракин А.В. Актуальные проблемы науки административного права. - М., 2011.

7. Куракин А.В. Административное право: проблемы теории и перспективы развития. - М., 2013.

8. Куракин А.В. Предмет административно-правового регулирования в механизме противодействия коррупции. - Домодедово, 2013.

9. Лесной В.М. Советская социалистическая законность. - М., 1959.

10. Шергин А.П. К концепции механизма административно-правового регулирования // Административное и административно-процессуальное право. - М., 2004.

\section{References (transliteration):}

1. Alekseev S.S. Mekhanizm pravovogo regulirovaniya $\mathrm{v}$ sotsialisticheskom gosudarstve. - M., 1966.

2. Alekseev S.S. Pravo. Opyt kompleksnogo issledovaniya. - M., 1999.

3. Atamanchuk G.V. Gosudarstvennoe upravlenie (organizatsionno-funktsional'nye voprosy). - M., 2000.

4. Kozlov Yu.M. Administrativnoe pravo. - M., 2002.

5. Kostennikov M.V., Kurakin A.V. Aktual'nye problemy administrativno-pravovogo regulirovaniya. - M., 2010.

6. Kostennikov M.V., Kurakin A.V. Aktual'nye problemy nauki administrativnogo prava. - M., 2011.

7. Kurakin A.V. Administrativnoe pravo: problemy teorii i perspektivy razvitiya. - M., 2013.

8. Kurakin A.V. Predmet administrativno-pravovogo regulirovaniya $\mathrm{v}$ mekhanizme protivodeystviya korruptsii. - Domodedovo, 2013.

9. Lesnoy V.M. Sovetskaya sotsialisticheskaya zakonnost'. - M., 1959.

10. Shergin A.P. K kontseptsii mekhanizma administrativnopravovogo regulirovaniya // Administrativnoe i administrativno-protsessual'noe pravo. - M., 2004. 